\title{
Measuring Systemic Risk in the Korean Banking Sector via Dynamic Conditional Correlation Models
}

\author{
Jaeho Yun* \\ Hyejung Moon**
}

The views expressed herein are those of the authors and do not necessarily reflect the official views of the Bank of Korea. When reporting or citing this paper, the authors' names should always be explicitly stated.

* Assistant Professor, Department of Economics, Ewha Womans University, 52, Ewhayeodae-gil, Seodaemun-gu, Seoul 120-750, Republic of Korea, Email: yunjaeho@ewha.ac.kr

** Economist, Systemic Risk Analysis Team, Marcroprudential Analysis Department, the Bank of Korea, 39, Namdaemunno 3-Ga, Jung-Gu, Seoul 100-794, Republic of Korea, Email: hjmoon@bok.or.kr

The authors especially thank Tae Soo Kang, Byung Hee Sung, Seung Hwan Lee and seminar participants at the Bank of Korea for their useful comments and suggestions. Professor Yun acknowledges the financial support and hospitality of the Bank of Korea. All remaining errors are our own. 


\section{Contents}

I . Introduction …................................................................ 1

II. Literature Review …..................................................... 3

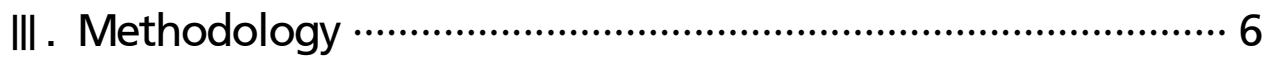

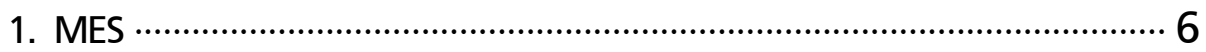

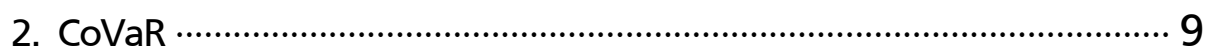

IV . Empirical Results …….................................................... 11

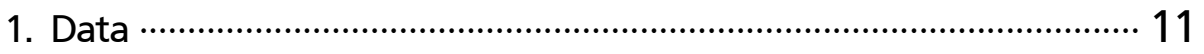

2. Estimation Results of the DCC Models ………................................ 12

3. Systemic Risk Contributions of Individual Banks ………………..... 15

4. Aggregate Systemic Risk Measures ……………………………... 25

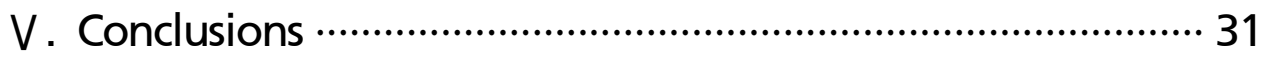

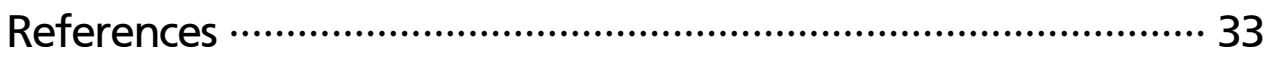




\section{Measuring Systemic Risk in the Korean Banking Sector via Dynamic Conditional Correlation Models}

In this paper we study systemic risks in the Korean banking sector by using two famous systemic risk measures - the MES (marginal expected shortfall) and CoVaR. To compute both measures we employ Engle's dynamic conditional correlation model. Our empirical analysis shows, first, that although these two systemic risk measures differ in defining the contributions to systemic risk, both are qualitatively very similar in explaining the cross-sectional differences in systemic risk contributions across banks. Second, we find that systemic risk contributions are closely related to certain bank characteristic variables (e.g., VaR (value at risk), size and leverage ratio). However, there are differences between the cross-sectional and the time series dimensions in the effects of these variables. Last, using a threshold VAR model, we suggest an overall systemic risk measure - the aggregate MES - and its associated threshold value for use as an early warning indicator.

Keywords: Systemic Risk, DCC (dynamic conditional correlation) model, MES (marginal expected shortfall), CoVaR, Threshold VAR

JEL Classification: C22, G21, G28 


\section{Introduction}

Recently there has been active research measuring systemic risks. As a lesson from the global financial crisis, it has been recognized that a banking supervision that focuses only on individual financial institutions may neglect the contributions to systemic risk of individual financial institutions. In particular, there have been some studies on the measurement of systemic risks using financial market variables such as equity prices or credit default swap (CDS) spreads, to make use of the forward-looking nature of financial market variables.

In this paper we investigate two systemic risk measures - the MES (marginal expected shortfall) and the CoVaR - which utilize equity market information. We apply both measures to the Korean banking sector. Until now, research on systemic risk has been mainly focused on the US financial system, which is characterized by the market-based "shadow banking" system. In contrast, main players in Korean financial system are still commercial banks. Thus we may have results different from the existing studies when the bank-based financial system is analyzed through the lens of systemic risk. Our result may have important implications for other bankbased financial systems.

The MES has been employed by Acharya et al. (2010) and Brownlees and Engle (2012) to evaluate the systemic risk contributions of individual financial institutions. The CoVaR was proposed for the first time by Adrian and Brunnermeier in 2008, who computed the CoVaR by a quantile regression method. Since then, many applications of the CoVaR have been implemented to measure various economies' systemic risks. Particularly, Girardi and Ergun (2013) estimate the CoVaR by multivariate GARCH models. Details will be discussed in the next section.

The two systemic risk measures are different in the ways in which they view the contribution to systemic risk of an individual financial institution. The MES defines the systemic risk contribution as the expected equity returns of an individual financial institution conditional on the market being distressed (e.g., when daily market returns are below $-2 \%$ ). The CoVaR is on the other hand defined as the VaR (value-at-risk) of the market returns (e.g., the $5 \%$ quantile of the conditional distribution of the daily market returns) conditional on the distress of a financial 
institution (e.g., when the equity return of that institution is at its VaR). In sum, the two measures differ in their directions given to the "cause and effect" behind systemic risk. On the "cause" side, the MES puts the distress of the market while the CoVaR places the distress of an individual financial institution. Both measures are popularly used systemic risk measures, and it is therefore important to understand how differently they evaluate the systemic risk contributions of financial institutions.

In addition to evaluating the systemic risk contributions of Korean banks via these two systemic risk measures, we propose an overall systemic risk indicator using the aggregate MES, since unlike the CoVaR measure the MES provides a reasonable economic interpretation. We can interpret the aggregate MES as the marginal expected shortfall of the returns of a portfolio consisting of individual banks' equities when the market returns fall below a certain threshold level. This aggregate systemic risk measure is similar in spirit to the overall SRISK index in Brownlees and Engle (2012). The overall SRISK index will be described in the next section. To use the aggregate MES for an early warning system, we apply a threshold VAR model to analyze the dynamic relationship between the systemic risk indicator and real economic activity. From analysis of this threshold VAR model, we can obtain a threshold value that can trigger a warning signal of financial instability.

To compute both systemic risk measures we use the dynamic conditional correlation (DCC) models proposed by Engle (2002), which are types of multivariate GARCH models. The multivariate GARCH models have an advantage in capturing the time-varying systemic risk exposure of a financial institution or the market - an advantage not shared by the quantile regression method that has also been very popular for measuring systemic risk. To compute the MES and the CoVaR measures, we depend respectively on Brownlees and Engle (2012) and Girardi and Ergun (2013). However, unlike their original methods we use the Monte Carlo simulation method to compute both systemic risk measures.

Our empirical analysis finds the following. First, that although the two systemic risk measures differ in defining systemic risk contributions, both are qualitatively very similar in explaining the cross-sectional differences in systemic risk contributions across banks. Second, that the systemic risk contributions are closely related to some bank characteristic variables (e.g., VaR, size and leverage ratio). 
However, there are differences between the cross-sectional and the time series dimensions in the effects of these variables. Lastly, that the dynamic relationship between financial shocks and real economic activity may vary substantially when the aggregate MES exceeds a certain threshold. The aggregate MES and its associated threshold value suggested in this paper are expected to offer useful information for financial instability monitoring.

The remainder of this paper is organized as follows. Section 2 selectively reviews the existing studies of systemic risk measurement using financial market information. Section 3 explains how the MES and the CoVaR are computed. Section 4 presents the results of empirical analysis, and Section 5 draws conclusions.

\section{Literature Review}

Adrian and Brunnermeier (2011) propose a pioneering systemic risk method called the CoVaR. ${ }^{1)}$ The CoVaR is the VaR of the financial system conditional on institutions being under distress. They model the joint dynamics of the equity returns of individual financial institutions and of the financial system using a quantile regression method. To be specific, they define an institution's contribution to systemic risk as the difference between the CoVaR conditional on that institution being under distress and the CoVaR when the institution is in a normal state. They denote the difference by $\Delta \mathrm{CoVaR}$, and find that in the time series dimension there is a very strong relationship between an individual institution's VaR and its $\triangle \mathrm{CoVaR}$. In the cross sectional dimension, however, their relationship turns out to be only weak.

Since the original study in 2008, the CoVaR has been widely used to measure systemic risks for diverse economies.2) One of the notable studies was done by Girardi and Ergun (2013), who in their CoVaR analysis change the definition of financial distress from "an institution being exactly at its VaR" to it "being at most at

1) The CoVaR was first proposed in 2008.

2) Adrian and Brunnermeier (2011) provide the list of applications of the CoVaR. 
its VaR," in order to consider more severe distress events and improve the consistency (monotonicity) of the dependence parameter. They use a multivariate GARCH model to capture the time-varying systemic risk exposure of an individual institution. Unlike Adrian and Brunnermeier (2011), Girardi and Ergun (2013) find that VaR and $\Delta \mathrm{CoVaR}$ are only weakly related in the time series as well as in the cross section. As they argue, this provides important implications for regulatory policies. Capital requirements determined based only on an institution's VaR could differ substantially from those that consider the systemic risk contribution of each bank, and the latter should be more important in determining capital requirements. Thus, the relationship between a bank's VaR and its systemic risk contribution is an important topic that we need to address in this paper.

While Adrian and Brunnermeier (2011) use equity returns as their input for measuring the CoVaR, CDS spreads have also been widely used to measure systemic risks. For instance, using CDS spreads Huang et al. (2009) estimate the expected default probability of a financial institution in a risk-neutral sense and propose, as a systemic risk measure, the distressed insurance premium (DIP). They also use the equity returns of individual financial institutions to model the simultaneous defaults of several institutions.

Performance comparisons between equity returns and CDS spreads have been implemented. Among them, Rodriguez-Moreno and Pena (2013) show that the systemic risk measures based on CDS spreads outperform those based on equity returns. However, using CDS spreads for measuring systemic risk in the Korean banking sector may not be as effective as in the US banking system. Choi (2011) for instance argues that CDS spreads may not be reliable because the trading volumes of CDS for individual financial institution bonds are relatively small in Asian emerging markets. He points out that there is accordingly only a little difference between the CDS spreads of 5-year Foreign Exchange Stabilization Bonds (among the government bonds denominated in US dollars) and those of the bonds issued by banks in Korea. Considering this point, caution is necessary in using CDS spreads in measuring systemic risk in Asian emerging markets, and this paper thus uses equity returns instead. As is well known, the issue of market liquidity related to the equity market in Korea does not arise. 
In addition to the CoVaR, we also study the MES as a systemic risk measure. Acharya et al. (2010) use the MES as an input to their systemic risk measure called the SES (systemic expected shortfall). The SES, which is used to measure a financial institution's systemic risk contribution, is defined as an individual bank's propensity to be undercapitalized when the financial system as a whole is undercapitalized. They assume that capital shortages of individual financial institutions when the overall financial system is unstable can impose an externality on the rest of the economy. They estimate the ex ante MES and leverage using daily equity returns from the year prior to the global financial crisis, which they then use to explain the cross-sectional variations in equity returns performances during the crisis.

Subsequently, Brownlees and Engle (2012) also argue that a financial institution that is highly likely to be unstable when the financial system is unstable tends to have a high degree of contribution to systemic risk. They however propose a new methodology, by arguing that it is not likely that regression estimates based on the global financial crisis will offer suitable guidance in a future crisis. Like Girardi and Ergun (2013), Brownlees and Engle (2012) also employ the dynamic conditional correlation (DCC) model proposed by Engle (2002) to model the relationship between individual institutions' equity returns and the market index returns. Brownlees and Engle (2012) consider an institution's MES and its leverage as components of their systemic risk measure called the SRISK. One of the useful properties of the SES (or MES) is its additivity, under which the sum of individual institutions' risks is identical to the overall systemic risk. According to Brownlees and Engle's (2012) approach, individual institutions' systemic risk contributions, called SRISK, are calculated and the systemic risk of the financial system is then obtained by summing up the individual SRISKs, and this can then be used as an early warning indicator for financial stability. Because of the additivity property, Brownlees and Engle's (2012) systemic risk measures can have some advantage over the CoVaR measures, in the sense that they provide an overall systemic risk measure. We also exploit the additivity property of the MES measure in our study. 


\section{Methodology}

\section{MES}

Our MES (marginal expected shortfall) measures are computed based on Brownlees and Engle (2012). As noted above, the MES is used to measure the contribution of each bank to overall systemic risk. According to Brownlees and Engle (2012), the MES at date $t$ is defined as

$$
\operatorname{MES}_{i, t}(C)=E_{t-1}\left[R_{i, t} \mid R_{m, t}<C\right]
$$

where $R_{m, t}$ and $R_{i, t}$ indicate the daily market index return (e.g., KOSPI 200 index returns) and a specific bank $i$ 's daily equity returns at date $t$, respectively. In Equation (1), $C$ is a threshold value to represent the systemic event and, like in Brownlees and Engle (2012), set to $-2 \%$.

As explained earlier, in order to estimate the MES we employ the DCC (dynamic conditional correlation) model developed by Engle (2002). The conditional means for both the market and an individual bank's equity returns are assumed as AR(1) processes. We denote them by $\mu_{m, t}$ and $\mu_{i, t}$, respectively. We then estimate univariate GARCH models by using the residuals filtered by the AR(1) models, and thus now consider a bivariate process of the market and a bank's equity returns as:

$$
\begin{aligned}
& R_{m, t}=\mu_{m, t}+\sigma_{m, t} \epsilon_{m, t} \\
& R_{i, t}=\mu_{i, t}+\sigma_{i, t} \rho_{i, t} \epsilon_{m, t}+\sigma_{i, t} \sqrt{1-\rho_{i, t}^{2}} \eta_{i, t}
\end{aligned}
$$

where $\epsilon_{m, t}$ and $\eta_{i, t}$ are assumed to be independent error terms. ${ }^{3)}$ Note that $\epsilon_{m, t}$ and $\eta_{i, t}$ can be easily obtained via Choleski factorization. The above specification in Equation (2) amounts to the conditional capital asset pricing model (CAPM) with time-varying betas. That is, Equation (2) can also be written as

3) Brownlees and Engle (2012) assume that $\epsilon_{m, t}$ and $\eta_{i, t}$ have zero correlation but no independence. Hence they allow tail dependence. 


$$
\begin{aligned}
R_{i, t} & =\mu_{i, t}+\sigma_{i, t} \rho_{i, t} \epsilon_{m, t}+\sigma_{i, t} \sqrt{1-\rho_{i, t}^{2}} \eta_{i, t} \\
& =\mu_{i, t}+\frac{\operatorname{cov}_{t-1}\left(R_{m, t}, R_{i, t}\right)}{\sigma_{m, t}^{2}}\left(R_{m, t}-\mu_{m, t}\right)+\sigma_{i, t} \sqrt{1-\rho_{i, t}^{2}} \eta_{i, t} \\
& =\mu_{i, t}+\beta_{i, t}\left(R_{m, t}-\mu_{m, t}\right)+\sigma_{i, t} \sqrt{1-\rho_{i, t}^{2}} \eta_{i, t}
\end{aligned}
$$

where $\beta_{i, t}$ is a time-varying beta coefficient. Therefore, the bivariate model can be interpreted as a dynamic conditional beta model, which allows the beta coefficient seen in a general CAPM to be time-varying. ${ }^{4)}$ In this way, our DCC specification can capture the time-varying nature of systemic risk exposure for each bank.

The conditional volatilities and correlations of the bivariate process defined in Equation (2) are modeled as follows:

$$
\operatorname{Var}_{t-1}\left(\begin{array}{c}
R_{i, t} \\
R_{m, t}
\end{array}\right)=D_{i, t} P_{i, t} D_{i, t}=\left[\begin{array}{cc}
\sigma_{i, t} & 0 \\
0 & \sigma_{m, t}
\end{array}\right]\left[\begin{array}{cc}
1 & \rho_{i, t} \\
\rho_{i, t} & 1
\end{array}\right]\left[\begin{array}{cc}
\sigma_{i, t} & 0 \\
0 & \sigma_{m, t}
\end{array}\right]
$$

For the individual GARCH processes we employ a threshold GARCH model, which was proposed by Glosten et al. (1993), that can capture a negative relationship between the volatilities and equity returns. To be specific, the conditional volatility dynamics are specified by

$$
\begin{aligned}
\sigma_{m, t}^{2} & =\omega_{m}+\alpha_{m} r_{m, t-1}^{2}+\gamma_{m} r_{m, t-1}^{2} I_{m, t-1}+\beta_{m} \sigma_{m, t-1}^{2} \\
\sigma_{i, t}^{2} & =\omega_{i}+\alpha_{i} r_{i, t-1}^{2}+\gamma_{i} r_{i, t-1}^{2} I_{i, t-1}+\beta_{i} \sigma_{i, t-1}^{2}
\end{aligned}
$$

where $r_{m, t}=R_{m, t}-\mu_{m, t}, r_{i, t}=R_{i, t}-\mu_{i, t}$, and $I_{m, t}$ is an indicator function that has a value of 1 if $r_{m, t}<0$, and $I_{i, t}$ is defined in the same manner. In Equation (5), $\gamma$ is a coefficient to capture the leverage effect. Given that the conditional volatilities are estimated using the threshold GARCH model, the conditional

4) Strictly speaking, excess returns (return minus risk-free rate) should be used in order for $\beta_{i, t}$ in Equation (3) to be interpreted as a conditional beta of the CAPM. However, the effect of the risk-free interest rate is expected to be small for a short period such as daily frequency. 
correlations are estimated using the following DCC model of Engle (2002):

$$
\left[\begin{array}{cc}
1 & \rho_{i, t} \\
\rho_{i, t} & 1
\end{array}\right]=\operatorname{diag}\left(Q_{i, t}\right)^{-(1 / 2)} Q_{i, t} \operatorname{diag}\left(Q_{i, t}\right)^{-(1 / 2)}
$$

Here $Q_{i, t}$ follows a process of

$$
Q_{i, t}=\left(1-\alpha_{C}-\beta_{C}\right) S_{i}+\alpha_{C} \epsilon_{i, t-1}^{*} \epsilon_{i, t-1}^{*^{\prime}}+\beta_{C} Q_{i, t-1}
$$

where $\epsilon_{i, t-1}^{*}$ is a standardized residual with unit variance as below:

$$
\epsilon_{i, t-1}^{*}=\left(R_{i, t-1}-\mu_{i, t-1}\right) / \sigma_{i, t-1}
$$

and $S_{i}$ denotes an unconditional correlation.

Given the conditional volatilities and correlations, we can then estimate the MES at date t. Given Equation (2) and the threshold value $C$, the MES is represented as

$$
\begin{aligned}
\operatorname{MES}_{i, t}(C)= & E_{t-1}\left[R_{i, t} \mid R_{m, t}<C\right] \\
= & \mu_{i, t}+\sigma_{i, t} E_{t-1}\left[\rho_{i, t} \epsilon_{m, t}+\sqrt{1-\rho_{i, t}^{2}} \eta_{i, t} \mid \epsilon_{m, t}<\frac{C-\mu_{m, t}}{\sigma_{m, t}}\right] \\
= & \mu_{i, t}+\sigma_{i, t} \rho_{i, t} E_{t-1}\left[\epsilon_{m, t} \mid \epsilon_{m, t}<\frac{C-\mu_{m, t}}{\sigma_{m, t}}\right] \\
& +\sigma_{i, t} \sqrt{1-\rho_{i, t}^{2}} E_{t-1}\left[\eta_{i, t} \mid \epsilon_{m, t}<\frac{C-\mu_{m, t}}{\sigma_{m, t}}\right] \\
& =\mu_{i, t}+\sigma_{i, t} \rho_{i, t} E_{t-1}\left[\epsilon_{m, t} \mid \epsilon_{m, t}<\frac{C-\mu_{m, t}}{\sigma_{m, t}}\right]
\end{aligned}
$$

We obtain the fourth equality because $\epsilon_{m, t}$ and $\eta_{i, t}$ are assumed to be independent.5) As shown in Equation (9), the distribution of $\epsilon_{m, t}$ (and $\eta_{i, t}$ under a no

5) Brownlees and Engle (2012) allow tail dependence between $\epsilon_{m, t}$ and $\eta_{i, t}$. However, according to their 
independence assumption) has to be specified in order to calculate the MES. In this paper we use an empirical distribution in order to take into account the fat tails observed in equity returns. ${ }^{6)}$ In other words, we collect $\left\{\epsilon_{m, t}\right\}$ from the outcome of the DCG estimation, and conduct the following Monte Carlo integration to compute the conditional expectation in the last line of Equation (9):

$$
E_{t-1}\left[\epsilon_{m, t} \mid \epsilon_{m, t}<\frac{C-\mu_{m, t}}{\sigma_{m, t}}\right] \approx \frac{1}{\tau} \sum_{t=1}^{T} \widehat{\epsilon_{m, t} I}\left[\widehat{\epsilon_{m, t}}<\frac{C-\mu_{m, t}}{\sigma_{m, t}}\right]
$$

where $I[\cdot]$ is an indicator function that takes 1 if the argument is true and takes zero otherwise.

\section{CoVaR}

As noted, our CoVaR measure is based on Girardi and Ergun (2013). First, Girardi and Ergun (2013) define the value-at-risk of a bank $i\left(\operatorname{VaR}_{q, t}^{i}\right)$ as the $q$-th quantile of the return distribution

$$
\operatorname{Pr}\left(R_{i, t} \leq \operatorname{VaR}_{q, t}^{i}\right)=q
$$

The CoVaR is now defined as

$$
\operatorname{Pr}\left(R_{m, t} \leq \operatorname{CoVaR} R_{q, t}^{m \mid i} \mid R_{i, t} \leq \operatorname{VaR} R_{q, t}^{i}\right)=q
$$

The conditioning event is that the bank $i$ 's return is less than or equal to its VaR. The CoVaR is the $q$-th quantile of the market return conditional on this conditioning event. Note that this definition of the CoVaR differs from that of Adrian and Brunnermeier (2011), for whom the conditioning event is that a bank $i$ is exactly at its VaR. Girardi and Ergun (2013) argue that their new definition of the

out-of-sample study the model with the tail independence outperforms the model without it.

6) Differently from our simulation method, Brownlees and Engle (2012) use a nonparametric kernel estimation approach. 
CoVaR facilitates backtesting, and furthermore that the new CoVaR becomes a continuous and increasing function of the interdependence between the market and bank $i$, which the original CoVaR measure is not.

The systemic risk contribution of an individual bank $i$ can be measured by the following $\Delta \mathrm{CoVaR}$ measure:

$$
\triangle C o V a R_{q, t}^{m \mid i}=100 \times\left(C o V a R_{i, t}^{m \mid i}-C o V a R_{q, t}^{m \mid b^{i}}\right) / C o V a R_{q, t}^{m \mid b^{i}}
$$

The $\triangle \mathrm{CoVaR}$ here is the percentage difference of the VaR of the market conditional on the distressed state of bank $i$ from the VaR of the market conditional on the benchmark state of bank $i$, which is defined as $b^{i} \sim(\mu-\sigma \leq R \leq \mu-\sigma)$. The benchmark state $b^{i}$ indicates the event where the bank $i$ 's return lies between $\mu-\sigma$ and $\mu+\sigma$, i.e., $\mu-\sigma \leq R \leq \mu+\sigma$.

As in the computation of the MES measure, we also employ the DCC model. We have to consider the following specification in Equation (14), however, because, in contrast to the MES, the CoVaR considers the direction from an individual bank to the market:

$$
\begin{aligned}
& R_{i, t}=\mu_{i, t}+\sigma_{i, t} \epsilon_{i, t} \\
& R_{m, t}=\mu_{m, t}+\sigma_{m, t} \rho_{i, t} \epsilon_{i, t}+\sigma_{m, t} \sqrt{1-\rho_{i, t}^{2}} \eta_{m, t}
\end{aligned}
$$

Here, as in the MES, $\epsilon_{i, t}$ and $\eta_{m, t}$ are assumed to be independent error terms. In order to model the distributions of $\epsilon_{i, t}$ and $\eta_{m, t}$, Girardi and Ergun (2013) employ a certain parametric asymmetric distribution - i.e., Hansen's skewed $t$-distribution. They then analytically solve for the CoVaR and $\Delta \mathrm{CoVaR}$. Different from Girardi and Ergun (2013), and also as in the case with the MES, we use the empirical distributions of $\epsilon_{i, t}$ and $\eta_{m, t}$, for which we find the computer coding simpler.

For example, suppose that we wish to compute a $5 \%$ CoVaR. First we compute the CoVaR using Equation (14). From the outcomes of the DCC estimation, we then save $\left\{\widehat{\epsilon_{i, t}}\right\}$ and $\left\{\widehat{\eta_{m, t}}\right\}$. From $\left\{\widehat{\epsilon_{i, t}}\right\}$ we can compute the $5 \%$ quantile of $\widehat{\epsilon_{i, t}}$, and collect the values that are smaller than this $5 \%$ quantile. We denote this collection by $\left\{\widetilde{\epsilon_{i, t}}\right\}$. Now we draw $\epsilon_{i, t}$ from $\left\{\widetilde{\epsilon_{i, t}}\right\}$. For each generated $\epsilon_{i, t}$ we also draw $\eta_{m, t}$ 
from $\left\{\widehat{\eta_{m, t}}\right\}$. Given a simulated pair of $\epsilon_{i, t}$ and $\eta_{m, t}$, the conditional means $\left(\mu_{i, t}\right.$ and $\left.\mu_{m, t}\right)$, conditional volatilities $\left(\sigma_{i, t}\right.$ and $\left.\sigma_{m, t}\right)$ and conditional correlation $\left(\rho_{i, t}\right)$, we can obtain one realization of $R_{m, t}$. By iterating this procedure sufficiently many times (e.g., 10,000 times), we can obtain the CoVaR measure, i.e. the $5 \%$ quantile from the collection of simulated $R_{m, t}$ 's. The benchmark CoVaR can be computed in a similar manner. Thus, using the CoVaR and the benchmark CoVaR, we can compute $\Delta$ CoVaR as in Equation (13).

\section{Empirical Results}

\section{Data}

Among Korean banks, we study those whose stocks are listed on the Korea Exchange, with the resulting ten banks consisting of five nationwide banks (Woori, Korea Exchange, KB, Hana and Shinhan), four local banks (Daegu, Busan, Jeju and Chunbuk), and one specialized bank (the Industrial Bank of Korea). Among them, Woori, KB, Shinhan, Hana, Daegu and Busan were converted to financial holding companies during our sample period, and with the equity return data for some banks thus no longer available we use the equity returns for their holding companies instead. Since the data on these ten banks are simultaneously available during the period of July 2002 through March 2013, we study the systemic risks during this sample period.

We also use some bank characteristic data (e.g., financial statement data) for conducting our sample correlation and panel regression analyses below, which are available as quarterly data from the financial information system of the Financial Supervisory Service. In Section IV.4 we construct the aggregate MES on a monthly basis as an overall systemic risk indicator. For this purpose we need the monthly series of banks' book equities, which are obtained through linear interpolation of the quarterly data. 


\section{Estimation Results of the DCC Models}

We employ multivariate GARCH models in order to compute both the MES and the CoVaR measures. As mentioned, the DCC model of Engle (2002) is used. We avoid a detailed description of the DCC estimation results for want of space, but it is noteworthy that the leverage coefficients of their daily equity returns ( $\gamma$ 's in Equation (5)) are estimated as significant for six banks. In this regard, the leverage effect is thus necessary for modeling daily equity returns.

Figure 1 shows the main outcomes from the DCC estimations. For illustration purposes, we report the medians of the conditional correlations, conditional volatilities (standard deviations) and conditional betas over time. Among them, the top panel in Figure 1 shows the time-varying conditional correlation. As can be seen, there is considerable variation over time - ranging from 0.2 to 0.7 . As pointed out in the existing studies, conditional correlations tend to rise during periods of financial instability, and our study also shows the conditional correlation to have increased during times of systemic crisis such as the Korean credit card (2003), global financial (2008) and euro area fiscal (2011) crises. We can see that, during the euro area fiscal crisis in 2011 the level of conditional correlation is almost the same as its level during the global financial crisis in 2008.

The middle panel of Figure 1 plots the time series of the median of the conditional standard deviations of the banks' equity returns. If we define the VaR of a bank as in Equation (9), the conditional standard deviations will be very similar to the VaR measure. Thus, the conditional standard deviation of a bank will be the most relevant indicator in the case where banking prudential regulations are applied to the individual banks without taking into account the financial system as a whole. The rises in the conditional standard deviation are most evident during the times of the IT bubble bursting in the early 2000s and the global financial crisis in 2008 in particular. In contrast to the case with the conditional correlation, the level of the conditional standard deviation is not so high at the time of the 2011 euro area fiscal crisis.

Finally, the bottom panel of Figure 1 illustrates the time series of the median of banks' conditional betas. As mentioned above, since these conditional betas take into 
Figure 1: Conditional Correlation, Volatility and Beta
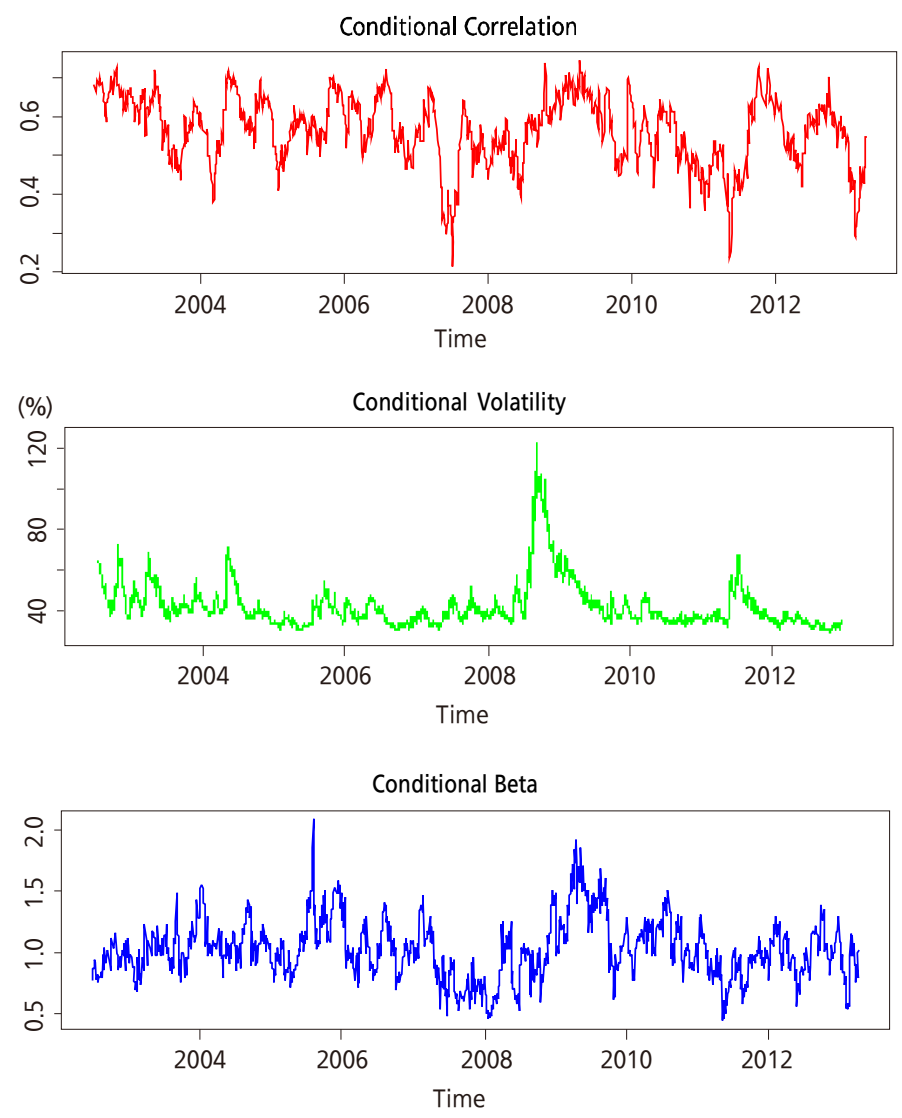

Note: The medians of the conditional correlations, volatilities and betas are drawn over time.

account both individual banks' correlations with the financial system and their conditional standard deviations, they are appropriate tools for evaluating individual banks' risks in the context of the financial system. As can be expected, the conditional beta is very high during the global financial crisis. It also exhibits a relatively high level during the euro area fiscal crisis. Considering the mild level of conditional standard deviations during 2011, this high level of conditional beta during the euro area fiscal crisis may be caused by the high level of conditional correlation. In this regard, if prudential regulations had been focused on the individual banks during this period, systemic risk could have been underestimated. Because the conditional beta is affected by both the correlation and the volatility, careful investigation will be 
Figure 2: Nationwide Banks vs. Local Banks
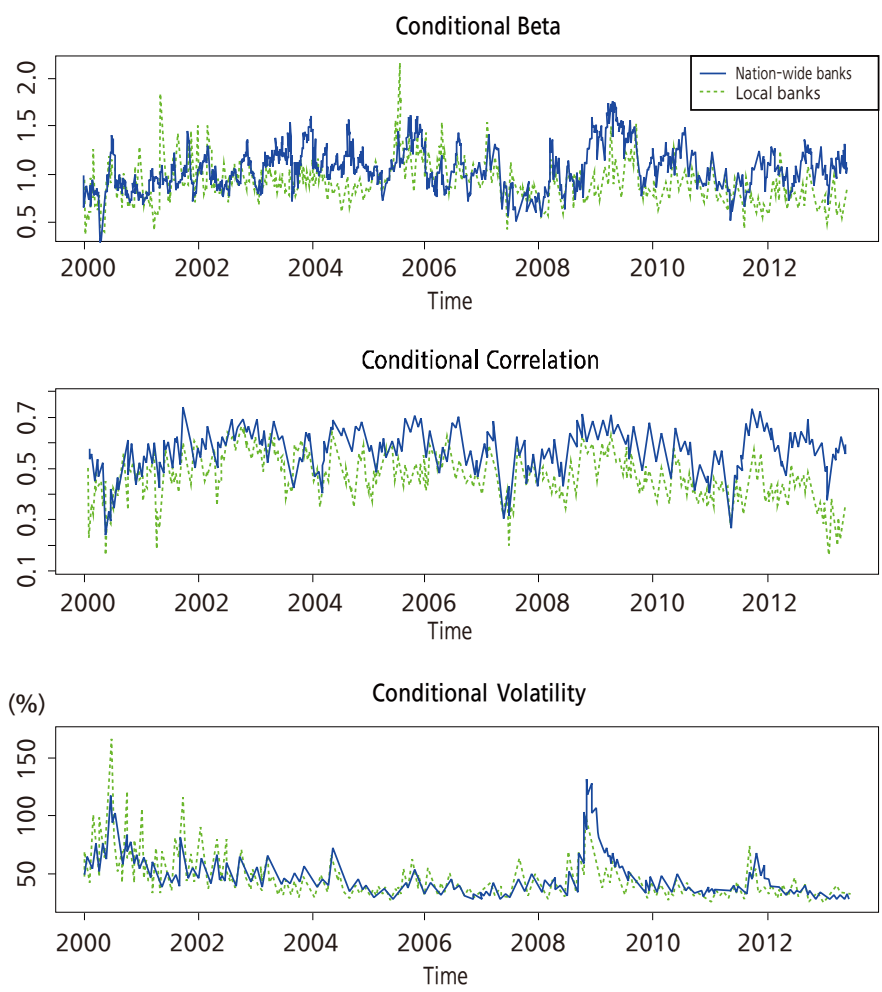

Note: The time series of the medians of the conditional betas, correlations and volatilities are drawn with blue solid lines for nationwide banks and with green dotted lines for local banks.

necessary to figure out the cause of any change in the beta.

Figure 2 compares the nationwide banks with local banks in terms of the correlations, volatilities and betas, which are also outcomes of the DCC estimation. Interestingly, in the volatilities in the bottom panel of Figure 2 there are no significant differences seen between nationwide and local banks. It is likely that the magnitudes of the VaRs of the two are very similar. A look at the correlation coefficients in the middle panel however finds systematically high correlations for nationwide banks. This explains the high betas of nationwide banks shown in the top panel, which implies larger systemic risk contributions from nationwide banks. 


\section{Systemic Risk Contributions of Individual Banks}

Using the DCC model, we estimate the daily MES and $\triangle \mathrm{CoVaR}$ measures for the ten Korean banks during 2002-2013. This section examines the estimation results, assesses the systemic risk contributions of individual banks in both the time series and the cross-sectional dimensions, and then compares the two systemic risk measures.

Figure 3 indicates the heterogeneities of both systemic risk measures across banks (top panel) and across time (bottom panel). For illustration purposes, we use the quarterly averages of both measures. First, the upper lefthand panel shows the heterogeneity of the MES measures across banks. We can see from the average MESs that, among these banks, two of them show systematically low MES levels while the other banks are at similar averages. Since the two exceptional banks here are both local banks, their low average MESs may be explained by their small sizes. The picture of $\triangle \mathrm{CoVaR}$ in the upper righthand panel also shows low averages for the $\triangle \mathrm{CoVaR}$ measures at the same two local banks. Compared with the MES, however, $\Delta \mathrm{CoVaR}$ demonstrates a somewhat larger variation in the averages across banks.

The lower panel of Figure 3 shows the trends of the two systemic risk measures over time. The averages are taken across banks at a given quarter. Compared with their heterogeneities across banks, both measures vary considerably across time, implying that both are substantially affected by the business cycle. As expected, during the periods of financial crisis the MES and $\triangle \mathrm{CoVaR}$ are at their highest levels. However, while the MES provides different magnitudes across different crises (e.g., the Korean credit card crisis (2003), the global financial crisis (2008), and the euro area fiscal crisis (2011)), the $\Delta \mathrm{CoVaR}$ is of similar magnitudes across different crisis episodes. The MES measure thus indicates different levels of systemic risk for different crises, for example identifying the global financial crisis as the period of highest systemic risk. 
Figure 3: Heterogeneity of MES and $\triangle \mathrm{CoVaR}$

(a) Heterogeneity across Banks

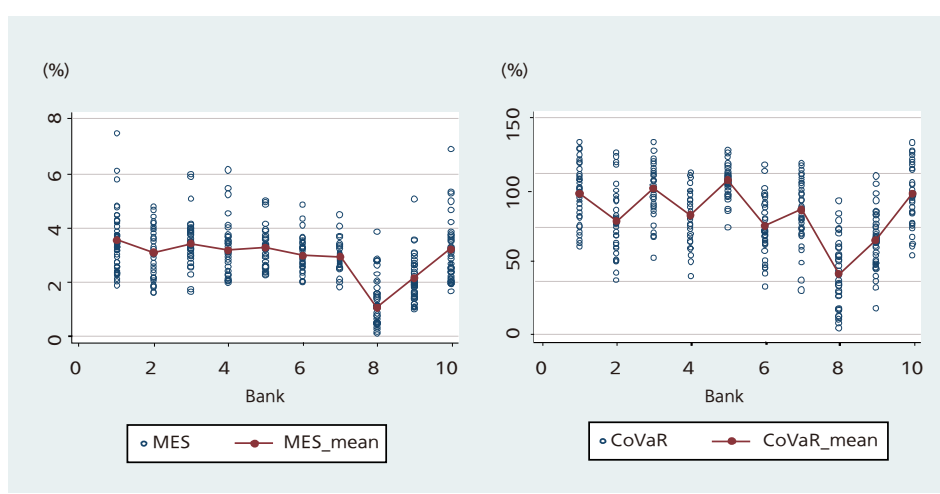

(b) Heterogeneity across Time
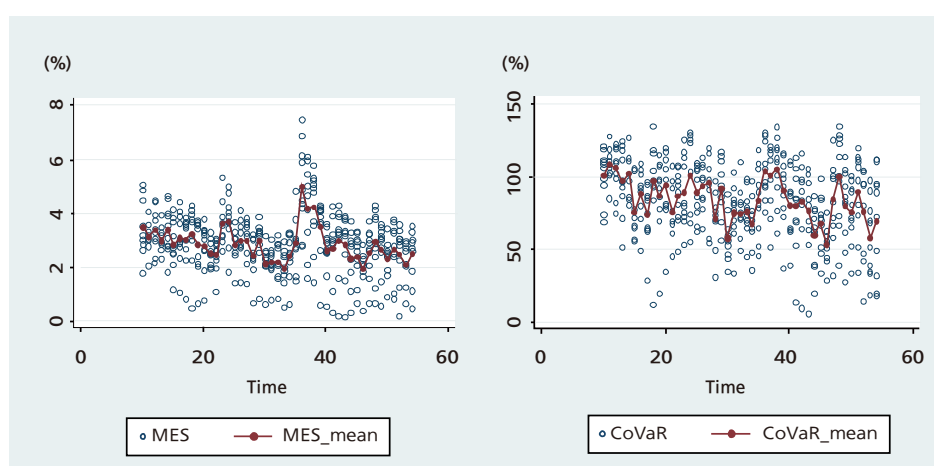

Note: The graphs are drawn based on the quarterly average of the MES and $\triangle$ CoVaR measures. In the upper-panel, the red line connects the average values of the MES or $\triangle \mathrm{CoVaR}$ measures across time for each bank. On the other hand, the red line connects the average values of the MES or $\triangle$ CoVaR measures across banks for each quarter in the lower panel.

Next we turn to assessing the systemic risk contributions of individual banks, and then compare the two systemic risk measures. Table 1 reports the long-run averages of the MES and $\triangle \mathrm{CoVaR}$ measures for the individual banks, and their corresponding rankings, during both the 2002-2007 and the 2008-2013 periods. As shown, the rankings in terms of systemic risk contributions of individual banks differ somewhat across the two systemic risk measures. However, it is observed that the MES and $\triangle \mathrm{CoVaR}$ for high-ranked banks are of very similar magnitudes. 
Table 1: Systemic Risk Contributions of Individual Banks

(\%)

\begin{tabular}{|c|cc|cc|cc|cc|cc|c|cc}
\hline \multicolumn{1}{c|}{ MES } & \multicolumn{1}{c|}{$\Delta$ CoVaR } \\
\hline Bank1 & 3.3 & $(3)$ & 3.8 & $(1)$ & 3.5 & $(1)$ & 97.9 & $(4)$ & 97.4 & $(3)$ & 97.7 & $(3)$ \\
\hline Bank2 & 3.4 & $(1)$ & 2.7 & $(8)$ & 3.1 & $(6)$ & 86.9 & $(6)$ & 70.2 & $(7)$ & 78.8 & $(7)$ \\
\hline Bank3 & 3.3 & $(2)$ & 3.5 & $(2)$ & 3.4 & $(2)$ & 104.2 & $(2)$ & 99.7 & $(2)$ & 102.0 & $(2)$ \\
\hline Bank4 & 2.9 & $(8)$ & 3.5 & $(3)$ & 3.2 & $(5)$ & 78.6 & $(8)$ & 86.3 & $(5)$ & 82.3 & $(6)$ \\
\hline Bank5 & 3.2 & $(4)$ & 3.3 & $(5)$ & 3.3 & $(3)$ & 107.6 & $(1)$ & 106.8 & $(1)$ & 107.2 & $(1)$ \\
\hline Bank6 & 3.0 & $(6)$ & 2.9 & $(7)$ & 3.0 & $(8)$ & 81.9 & $(7)$ & 68.8 & $(8)$ & 75.5 & $(8)$ \\
\hline Bank7 & 3.0 & $(7)$ & 3.0 & $(6)$ & 3.0 & $(7)$ & 92.7 & $(5)$ & 82.3 & $(6)$ & 87.6 & $(5)$ \\
\hline Bank8 & 1.4 & $(10)$ & 0.7 & $(10)$ & 1.1 & $(10)$ & 49.2 & $(10)$ & 33.4 & $(10)$ & 41.5 & $(10)$ \\
\hline Bank9 & 2.4 & $(9)$ & 1.7 & $(9)$ & 2.1 & $(9)$ & 73.6 & $(9)$ & 58.1 & $(9)$ & 66.0 & $(9)$ \\
\hline Bank10 & 3.2 & $(5)$ & 3.3 & $(4)$ & 3.3 & $(4)$ & 99.0 & $(3)$ & 96.1 & $(4)$ & 97.6 & $(4)$ \\
\hline
\end{tabular}

Note: The rankings are shown in parentheses.

Figure 4 plots scatter diagrams between the MES and $\triangle \mathrm{CoVaR}$ during both 2002-2007 and 2008-2013. We can see that both measures evaluate each bank's systemic risk contribution in a very similar way, and the correlations between the two measures during the two sample periods are 0.90 and 0.93 , respectively. Thus, in explaining cross-sectional differences in systemic risk contributions across banks, it seems that the MES and the $\Delta \mathrm{CoVaR}$ are qualitatively very similar.

We next investigate the relationships between the systemic risk measures and some bank characteristic variables. We use its VaR, log of equity, and leverage ratio as the bank characteristic variables. Like Girardi and Ergun (2013), we compute the VaR measures using Equation (11); they are thus outcomes of threshold GARCH estimation. As before, we use the sample periods of 2002-2007 and 2008-2013. We let the log of its total equity proxy the bank's size. Figure 5, first, is with respect to the MES measure. Interestingly, it shows a significant positive relationship between the MES and the VaR measures (with correlations of 0.45 and 0.89 , respectively, for the two subsamples). This result is in contrast with the case of US banks studied by Adrian and Brunnermeier (2011) and Girardi and Ergun (2013), who could not 
Figure 4: Comparisons between MES and $\triangle$ CoVaR

(2002-2007)

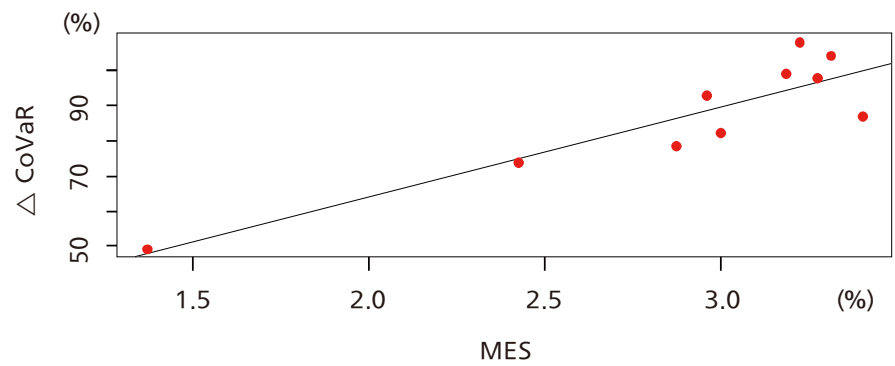

(2008-2013)

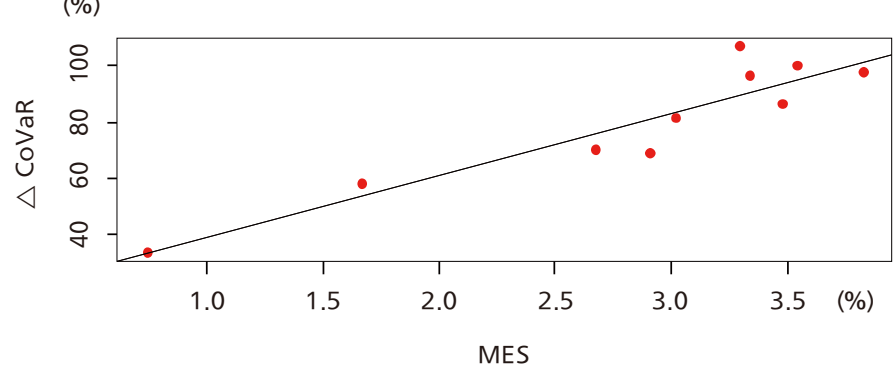

Note: Each red dot represents an individual bank's MES versus $\triangle$ CoVaR and a line is drawn as close as possible to all points.

find significant relationships between the VaR and the systemic risk contribution measures. We can also find a significant relationship between the bank size variable (i.e., the log of equity) and the MES (with correlations of 0.86 and 0.93 for the two subsamples). Rather unexpectedly, however, it is found likely that there is no significant positive relationship between the leverage ratio and the MES.

A similar analysis is conducted for the $\Delta \mathrm{CoVaR}$ measure, and as shown in Figure 6 we obtain results similar to those for the MES. The correlations between $\triangle \mathrm{CoVaR}$ and the $\log$ of equity are at high levels of 0.86 and 0.93 , respectively, for the two subsamples. However, the correlations with the VaR are relatively smaller than with the MES (at 0.15 and 0.69 , respectively). Similar to the case with the MES, the correlations between $\Delta \mathrm{CoVaR}$ and the leverage ratio are estimated as not significantly positive (at -0.44 and -0.01 , respectively). 
Figure 5: MES and Banks' Characteristics
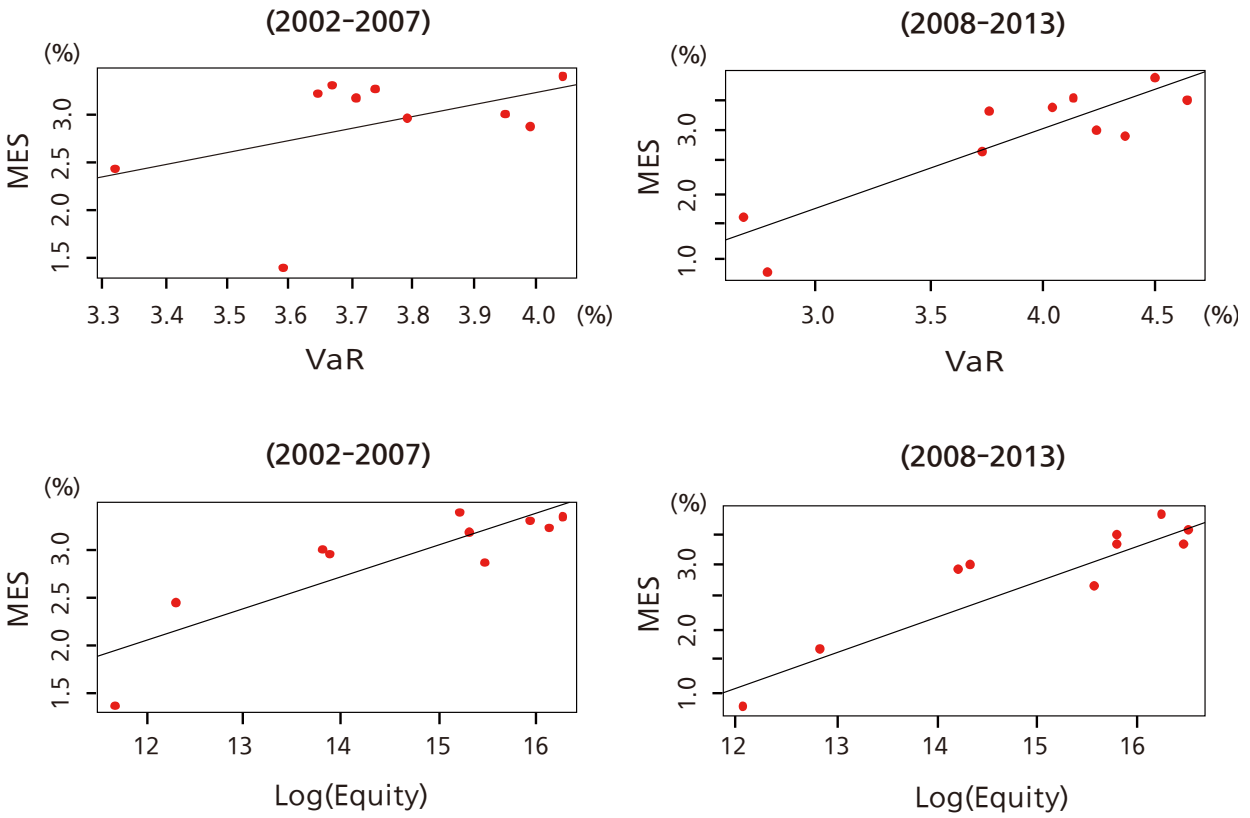

(2008-2013)

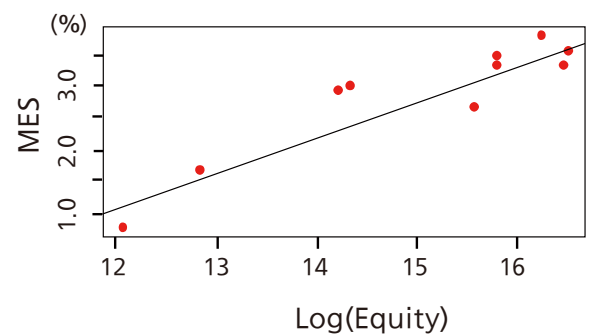

(2002-2007)

(2008-2013)
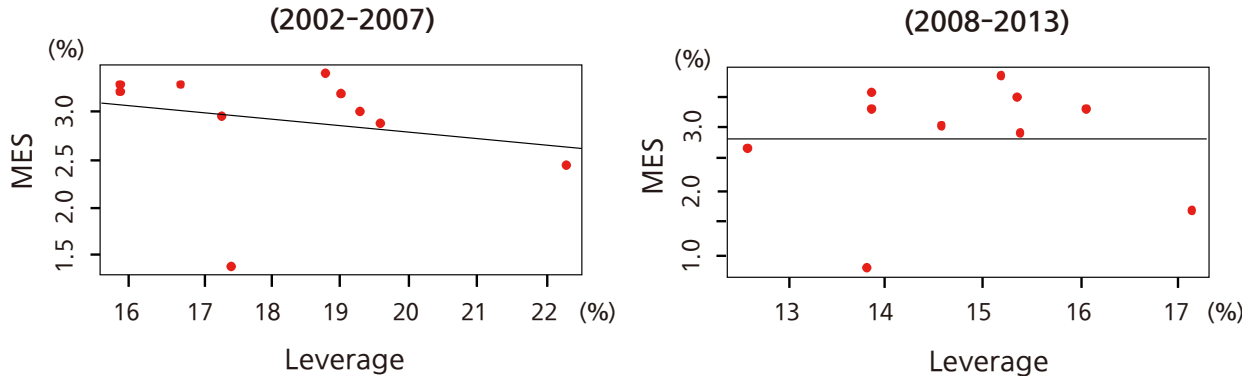

Note: The scatter diagrams plot the bank characteristic variable $(\mathrm{VaR}$, log of equity and leverage ratio) versus the MES, for during 2002-2007 and 2008-2013.

In the above analysis, the most important result is that the bank's size is significantly and positively associated with the systemic risk contribution of that bank. It is also notable that, different from the past studies undertaken on US banks, the relationships between the VaRs of individual banks and their systemic risk contributions are significantly positive. However, the relationship between the systemic risk contribution and the leverage ratio turns out to be weak for both the 
Figure 6: $\triangle$ CoVaR and Banks' Characteristics
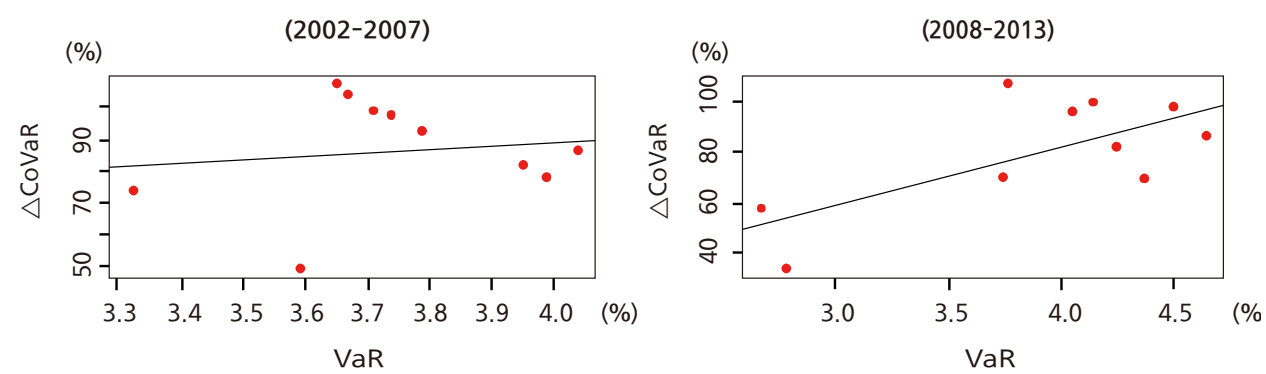

(\%)

(2002-2007)
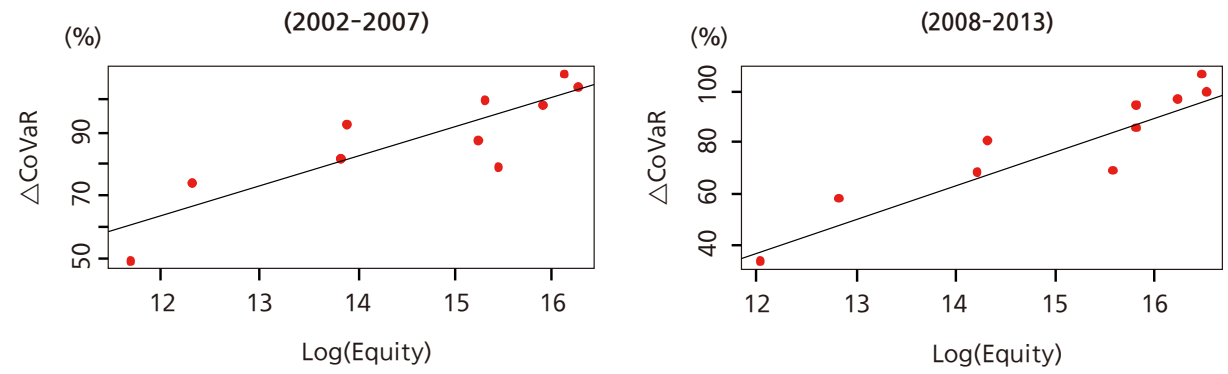

(\%)

(2002-2007)
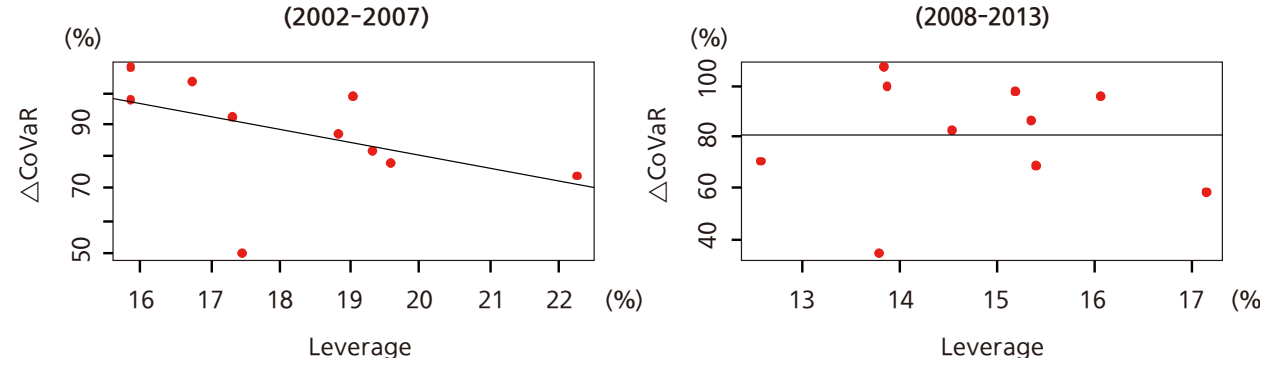

Note: The scatter diagrams plot the bank characteristic variable (VaR, log of equity and leverage ratio) versus $\Delta$ CoVaR, for during 2002-2007 and 2008-2013.

MES and $\triangle \mathrm{CoVaR}$. It should however be noted that, since we use long-run averages for each subsample, our analysis reveals only cross-sectional implications. We can thus only argue at most that, at least in the cross-sectional dimension, there is no substantial relationship between the leverage ratio and the contribution to systemic risk.

In order to find the main determinants of the contributions to systemic risk of individual banks in the time series as well as the cross-sectional dimension, we 
conduct a panel data regression analysis with quarterly data (i.e., from 2002.Q3 to 2013.Q1). For explanatory variables we employ each bank's characteristic variables, along with macro variables and financial market variables. To avoid the possible endogeneity problem, we use explanatory variables lagged by one quarter. For the dependent variables, we use the quarterly average of either the MES or $\triangle \mathrm{CoVaR}$. As control variables, moreover, we include each bank's financial statement variables reflecting liquidity, capital adequacy, profitability and asset quality. Considering that our data is a long panel with a small cross section and long time series, we do not include a time dummy among the explanatory variables. Rather, we use several macro and financial market variables to take into account the potential time effects. To address the robustness of our results, we employ several panel data estimation methods such as pooled OLS (POLS), a fixed effect (FE) model, a random effect (RE) model and a dynamic panel model (Arellano and Bond, 1992).7)

Table 2 reports the panel regression estimation results for the MES, showing that, except for the dynamic panel model, a lagged VaR turns out to have a significant positive effect on the MES. Notably, we obtain a significant coefficient for the lagged VAR even in the fixed effect model that captures the time series effect of the explanatory variables. Thus, in our study, the VaR has a positive effect on the systemic risk contribution of an individual bank in the time-series dimension as well as the cross-sectional dimension. As noted above, this differs from the findings of past studies of Adrian and Brunnermeier (2011) and Girardi and Ergun (2013).

Importantly, we also obtain positive and significant coefficients for the leverage ratio across all models considered. Recall that, in the pure cross-sectional analysis discussed above, we could not find a significantly positive relationship between the measures of systemic risk contribution and the leverage ratio. It seems, however, in the time-series context, that a higher leverage ratio at a bank tends to increase its contribution to systemic risk over time. Along with this result, it is also notable that the BIS capital adequacy ratio does not have a significant effect on the MES across all models. It has been argued that the role of the BIS capital adequacy ratio is

7) Among the Pooled OLS, fixed effect and random effect models, we find as results of both the Breusch and Pagan test and the Hausman test that the fixed effect model is the most suitable. 
limited, due to its pro-cyclical nature as well as to regulatory arbitrage. Consistent with this argument, after controlling for the effect of the leverage ratio we cannot find any significant effect of the BIS capital adequacy ratio.

In the cross-sectional analysis considered above, the size of a bank, which is proxied by the log of its equity, greatly affects the systemic risk contribution of that bank. However, in the results of estimation using the fixed effect and the dynamic panel models, which by construction remove the effects of time-invariant latent variables, the size of the bank loses its explanatory power over its systemic risk contribution. We have a significant positive coefficient for the log equity variable only in the Pooled OLS and random effect models, which can reflect the influences of time-invariant heterogeneity across banks. It therefore seems that the size of a bank is associated with its contribution to systemic risk only in the cross-sectional dimension.

Table 2 shows in addition that there are many macro and financial market variables which affect the MES to significant extents. Thus, consistent with the results in Figure 3, banks' systemic risk contributions prove to be closely associated with the business cycle.

Table 3 reports the determinants of the $\triangle \mathrm{CoVaR}$ measure. Since we obtain estimation results similar to those for the MES we skip detailed explanation, but should note that, in the case of $\Delta \mathrm{CoVaR}$, the relationship with the leverage effect is not as substantial as in the case of the MES. Only the random effect model provides a significant and positive coefficient for the leverage ratio.

It is also worth noting that, in the analyses in both Tables 2 and 3, we obtain positive coefficients for the lagged GDP growth rate and negative coefficients for the lagged KOSPI index returns. The former finding may imply that systemic risks may accumulate during economic booms. It is likely that the latter finding is due to the leverage effect, whereby an increase in stock prices tends to accompany a decrease in stock price volatility. 
Table 2: Determinants of MES

\begin{tabular}{|c|c|c|c|c|}
\hline & $\begin{array}{l}\text { POLS } \\
\mathrm{b} / \mathrm{se}\end{array}$ & $\begin{array}{r}F E \\
\mathrm{~b} / \mathrm{se}\end{array}$ & $\begin{array}{r}\mathrm{RE} \\
\mathrm{b} / \mathrm{se}\end{array}$ & $\begin{array}{l}A B \\
b / s e\end{array}$ \\
\hline L. VaR & $\begin{array}{l}0.364^{* * *} \\
(0.05)\end{array}$ & $\begin{array}{l}0.336^{* * *} \\
(0.04)\end{array}$ & $\begin{array}{l}0.364^{* * *} \\
(0.04)\end{array}$ & $\begin{array}{c}0.096 \\
(0.06)\end{array}$ \\
\hline L. LogEquity & $\begin{array}{l}0.438^{* * *} \\
(0.06)\end{array}$ & $\begin{array}{c}-0.022 \\
(0.11)\end{array}$ & $\begin{array}{l}0.438^{* * *} \\
(0.00)\end{array}$ & $\begin{array}{c}0.049 \\
(0.10)\end{array}$ \\
\hline L.Leverage & $\begin{array}{l}0.099^{* *} \\
(0.02)\end{array}$ & $\begin{array}{l}0.062^{* * *} \\
(0.01)\end{array}$ & $\begin{array}{l}0.099^{* * *} \\
(0.01)\end{array}$ & $\begin{array}{l}0.057^{* * *} \\
(0.02)\end{array}$ \\
\hline L. LDratio & $\begin{array}{c}-0.003^{*} \\
(0.00)\end{array}$ & $\begin{array}{c}-0.004^{*} \\
(0.00)\end{array}$ & $\begin{array}{l}-0.003^{* *} \\
(0.00)\end{array}$ & $\begin{array}{l}-0.004^{* * *} \\
(0.00)\end{array}$ \\
\hline L.BISratio & $\begin{array}{c}-0.055 \\
(0.03)\end{array}$ & $\begin{array}{c}-0.034 \\
(0.03)\end{array}$ & $\begin{array}{c}-0.055 \\
(0.03)\end{array}$ & $\begin{array}{r}-0.048 \\
(0.03)\end{array}$ \\
\hline L. NPLratio & $\begin{array}{c}-0.022 \\
(0.05)\end{array}$ & $\begin{array}{c}-0.050 \\
(0.05)\end{array}$ & $\begin{array}{c}-0.022 \\
(0.05)\end{array}$ & $\begin{array}{c}-0.043 \\
(0.06)\end{array}$ \\
\hline L.ROA & $\begin{array}{l}0.298^{*} \\
(0.13)\end{array}$ & $\begin{array}{l}0.072 \\
(0.12)\end{array}$ & $\begin{array}{l}0.298^{*} \\
(0.14)\end{array}$ & $\begin{array}{c}0.135 \\
(0.11)\end{array}$ \\
\hline L.GDP & $\begin{array}{l}0.107^{* *} \\
(0.03)\end{array}$ & $\begin{array}{l}0.110^{* *} \\
(0.03)\end{array}$ & $\begin{array}{l}0.107^{* *} \\
(0.04)\end{array}$ & $\begin{array}{l}0.086^{* * *} \\
(0.02)\end{array}$ \\
\hline L.KOSPI & $\begin{array}{l}-0.006^{*} \\
(0.00)\end{array}$ & $\begin{array}{c}-0.007^{*} \\
(0.00)\end{array}$ & $\begin{array}{c}-0.006 \\
(0.00)\end{array}$ & $\begin{array}{l}-0.009^{* * *} \\
(0.00)\end{array}$ \\
\hline L.FX & $\begin{array}{l}0.040^{* * *} \\
(0.01)\end{array}$ & $\begin{array}{l}0.041^{* * *} \\
(0.01)\end{array}$ & $\begin{array}{l}0.040^{* * *} \\
(0.01)\end{array}$ & $\begin{array}{l}0.044^{* * *} \\
(0.01)\end{array}$ \\
\hline L.Vol_FX & $\begin{array}{l}0.557^{* *} \\
(0.15)\end{array}$ & $\begin{array}{l}0.704^{* * *} \\
(0.14)\end{array}$ & $\begin{array}{l}0.557^{* * *} \\
(0.14)\end{array}$ & $\begin{array}{l}0.680^{* * *} \\
(0.12)\end{array}$ \\
\hline L.Vol_KOSPI & $\begin{array}{c}-0.610^{* * *} \\
(0.10)\end{array}$ & $\begin{array}{l}-0.650^{* * *} \\
(0.11)\end{array}$ & $\begin{array}{l}-0.610^{* * *} \\
(0.11)\end{array}$ & $\begin{array}{c}-0.447^{* * *} \\
(0.10)\end{array}$ \\
\hline L. Housing & $\begin{array}{l}-0.030^{* *} \\
(0.01)\end{array}$ & $\begin{array}{c}-0.011 \\
(0.01)\end{array}$ & $\begin{array}{c}-0.030 \\
(0.03)\end{array}$ & $\begin{array}{r}-0.012 \\
(0.01)\end{array}$ \\
\hline L.MES & & & & $\begin{array}{l}0.325^{* * *} \\
(0.04)\end{array}$ \\
\hline constant & $\begin{array}{l}-5.272^{* *} \\
(1.15)^{2}\end{array}$ & $\begin{array}{l}2.219 \\
(1.47)\end{array}$ & $\begin{array}{c}-5.272^{* *} \\
(0.68)\end{array}$ & \\
\hline $\begin{array}{l}\text { R-sqr } \\
\text { dfes } \\
\text { BIC }\end{array}$ & $\begin{array}{r}0.669 \\
9 \\
848.2\end{array}$ & $\begin{array}{r}0.486 \\
9 \\
796.2\end{array}$ & & \\
\hline
\end{tabular}

Note: POLS, FE, RE and $A B$ stand for pooled OLS, a fixed effect model, a random effect model and a dynamic panel model (Arellano and Bond, 1992), respectively. Explanatory variables listed in the table are lagged by one quarter, so "L." is put in front of the variable names. The explanatory variables are $\mathrm{VaR}$, log of equity, leverage ratio, loan-deposit ratio, BIS capital adequacy ratio, non-performing loan ratio, return on assets, GDP, KOSPI, foreign exchange rate, volatility of foreign exchange rate, volatility of KOSPI and housing price. The symbols $*, * *$ and $* * *$ represent statistical significance at the $5 \%, 1 \%$ and $0.1 \%$ level, respectively. 
Table 3: Determinants of $\triangle$ CoVaR

\begin{tabular}{|c|c|c|c|c|}
\hline & $\begin{array}{l}\text { POLS } \\
\mathrm{b} / \mathrm{se}\end{array}$ & $\begin{array}{r}F E \\
b / s e\end{array}$ & $\begin{array}{r}\mathrm{RE} \\
\mathrm{b} / \mathrm{se}\end{array}$ & $\begin{array}{r}A B \\
b / s e\end{array}$ \\
\hline L.VaR & $\begin{array}{l}3.217^{*} \\
(1.27)\end{array}$ & $\begin{array}{l}3.979^{* *} \\
(1.00)\end{array}$ & $\begin{array}{l}3.217^{* *} \\
(1.09)\end{array}$ & $\begin{array}{l}2.915^{* * *} \\
(0.63)\end{array}$ \\
\hline L. LogEquity & $\begin{array}{l}11.145^{* * *} \\
(1.76)\end{array}$ & $\begin{array}{r}-11.360 \\
(5.75)\end{array}$ & $\begin{array}{l}11.145^{* * *} \\
(0.68)\end{array}$ & $\begin{array}{c}-9.050 \\
(5.13)\end{array}$ \\
\hline L. Leverage & $\begin{array}{l}1.900 \\
(0.99)\end{array}$ & $\begin{array}{c}-0.037 \\
(0.98)\end{array}$ & $\begin{array}{l}1.900^{* * * *} \\
(0.39)\end{array}$ & $\begin{array}{c}-0.199 \\
(0.75)\end{array}$ \\
\hline L. LDratio & $\begin{array}{c}-0.027 \\
(0.03)\end{array}$ & $\begin{array}{c}-0.092^{*} \\
(0.03)\end{array}$ & $\begin{array}{c}-0.027 \\
(0.02)\end{array}$ & $\begin{array}{l}-0.080^{* * *} \\
(0.02)\end{array}$ \\
\hline L. BISratio & $\begin{array}{c}-0.707 \\
(1.54)\end{array}$ & $\begin{array}{c}-0.596 \\
(1.02)\end{array}$ & $\begin{array}{c}-0.707 \\
(0.88)\end{array}$ & $\begin{array}{c}-1.114 \\
(0.71)\end{array}$ \\
\hline L.NPLratio & $\begin{array}{c}1.581 \\
(2.21)\end{array}$ & $\begin{array}{c}-0.621 \\
(1.90)\end{array}$ & $\begin{array}{r}1.581 \\
(1.28)\end{array}$ & $\begin{array}{c}-0.398 \\
(1.69)\end{array}$ \\
\hline L.ROA & $\begin{array}{l}7.943 \\
(3.65)\end{array}$ & $\begin{array}{r}0.791 \\
(3.81)\end{array}$ & $\begin{array}{l}7.943^{*} \\
(3.93)\end{array}$ & $\begin{array}{l}0.046 \\
(3.98)\end{array}$ \\
\hline L.GDP & $\begin{array}{l}2.320^{* *} \\
(0.67)\end{array}$ & $\begin{array}{l}2.406^{* *} \\
(0.51)\end{array}$ & $\begin{array}{l}2.320^{*} \\
(1.08)\end{array}$ & $\begin{array}{l}1.886^{* * *} \\
(0.37)\end{array}$ \\
\hline L. KOSPI & $\begin{array}{l}-0.256^{* *} \\
(0.06)\end{array}$ & $\begin{array}{l}-0.287^{* * *} \\
(0.06)\end{array}$ & $\begin{array}{c}-0.256^{*} \\
(0.12)\end{array}$ & $\begin{array}{l}-0.289^{* * *} \\
(0.05)\end{array}$ \\
\hline L.FX & $\begin{array}{c}0.334 \\
(0.16)\end{array}$ & $\begin{array}{l}0.381^{*} \\
(0.14)\end{array}$ & $\begin{array}{l}0.334 \\
(0.22)\end{array}$ & $\begin{array}{l}0.436^{* *} \\
(0.15)\end{array}$ \\
\hline L.Vol_FX & $\begin{array}{c}0.384 \\
(3.86)\end{array}$ & $\begin{array}{c}6.146 \\
(3.73)\end{array}$ & $\begin{array}{c}0.384 \\
(3.77)\end{array}$ & $\begin{array}{l}6.848^{*} \\
(2.97)\end{array}$ \\
\hline L.Vol_KOSPI & $\begin{array}{l}3.422 \\
(2.31)\end{array}$ & $\begin{array}{c}-1.549 \\
(2.22)\end{array}$ & $\begin{array}{l}3.422 \\
(3.00)\end{array}$ & $\begin{array}{r}-3.541 \\
(2.09)\end{array}$ \\
\hline L. Housing & $\begin{array}{c}-0.180 \\
(0.32)\end{array}$ & $\begin{array}{l}0.690 \\
(0.39)\end{array}$ & $\begin{array}{c}-0.180 \\
(0.69)\end{array}$ & $\begin{array}{c}0.661 \\
(0.37)\end{array}$ \\
\hline L. CoVaR & & & & $\begin{array}{l}0.227^{* * *} \\
(0.05)\end{array}$ \\
\hline constant & $\begin{array}{l}-125.535^{*} \\
(44.55)\end{array}$ & $\begin{array}{c}251.276^{*} \\
(97.61)\end{array}$ & $\begin{array}{l}-125.535^{* * *} \\
(18.71)\end{array}$ & \\
\hline $\begin{array}{l}\text { R-sqr } \\
\text { dfes } \\
\text { BIC }\end{array}$ & $\begin{array}{r}0.538 \\
9 \\
3573.3\end{array}$ & $\begin{array}{r}0.334 \\
9 \\
3432.7\end{array}$ & & \\
\hline
\end{tabular}

Note: POLS, FE, RE and $A B$ stand for pooled OLS, a fixed effect model, a random effect model and a dynamic panel model (Arellano and Bond, 1992), respectively. Explanatory variables listed in the table are lagged by one quarter, so "L." is put in front of the variable names. The explanatory variables are VaR, log of equity, leverage ratio, loan-deposit ratio, BIS capital adequacy ratio, non-performing loan ratio, return on assets, GDP, KOSPI, foreign exchange rate, volatility of foreign exchange rate, volatility of KOSPI and housing price. The symbols $*, * *$ and $* * *$ represent statistical significance at the $5 \%, 1 \%$ and $0.1 \%$ level, respectively. 


\section{Aggregate Systemic Risk Measures}

One of the advantages of the MES is that it can be aggregated across banks, and the resulting aggregate provides a reasonable economic interpretation as the marginal expected shortfall of the return of the portfolio consisting of individual banks' equities conditional on the market returns being below a certain threshold level. We will denote this aggregate $\mathrm{MES}^{8}$ ) as the weighted average of individual banks' MES, where the weights of the individual banks are proportional to their equities. In this section we examine whether this aggregate MES can play the role of overall systemic risk measure. We hope that it can be used as an early warning indicator for the overall financial system, which $\Delta \mathrm{CoVaR}$ unfortunately cannot because it lacks this additivity.

Many policy decisions, including the central bank's policy rate determinations, are meanwhile made on a monthly basis, and many macroeconomic variables are also released on a monthly basis. It will thus be convenient if the overall systemic risk measures are constructed as monthly indicators, and considering this we construct a monthly overall systemic risk measure.

The upper panel of Figure 7 shows the trend of the aggregate MES over time. For comparison purposes, we also illustrate the aggregate $\triangle \mathrm{CoVaR}$ in the lower panel. The aggregate $\Delta \mathrm{CoVaR}$ is also computed as an equity-weighted average of the $\Delta$ CoVaRs of individual banks, although it is hard to find any economic meaning in the result. We can see that both aggregate measures tend to move together over time (the correlation is estimated to be 0.69 ). However, it seems that the aggregate $\Delta$ CoVaR cannot differentiate the extent of systemic risks across different crisis episodes. In contrast to the case with the aggregate MES, based on the aggregate $\triangle \mathrm{CoVaR}$ the global financial crisis is not distinguishable from other crises.

We focus now on the aggregate MES. From the upper panel of Figure 7 it can be seen that, after having increased with the global financial crisis, systemic risk later decreased but then rose again after the euro area fiscal crisis in 2011. And since then it has been declining steadily until now. As noted above, the aggregate MES

8) This is similar to the SRISK proposed by Brownlees and Engle (2012). They use the 6-month MES, the liability size, and the capital size as inputs for their SRISK measure. 
Figure 7: Aggregate MES and Aggregate $\triangle \mathrm{CoVaR}$
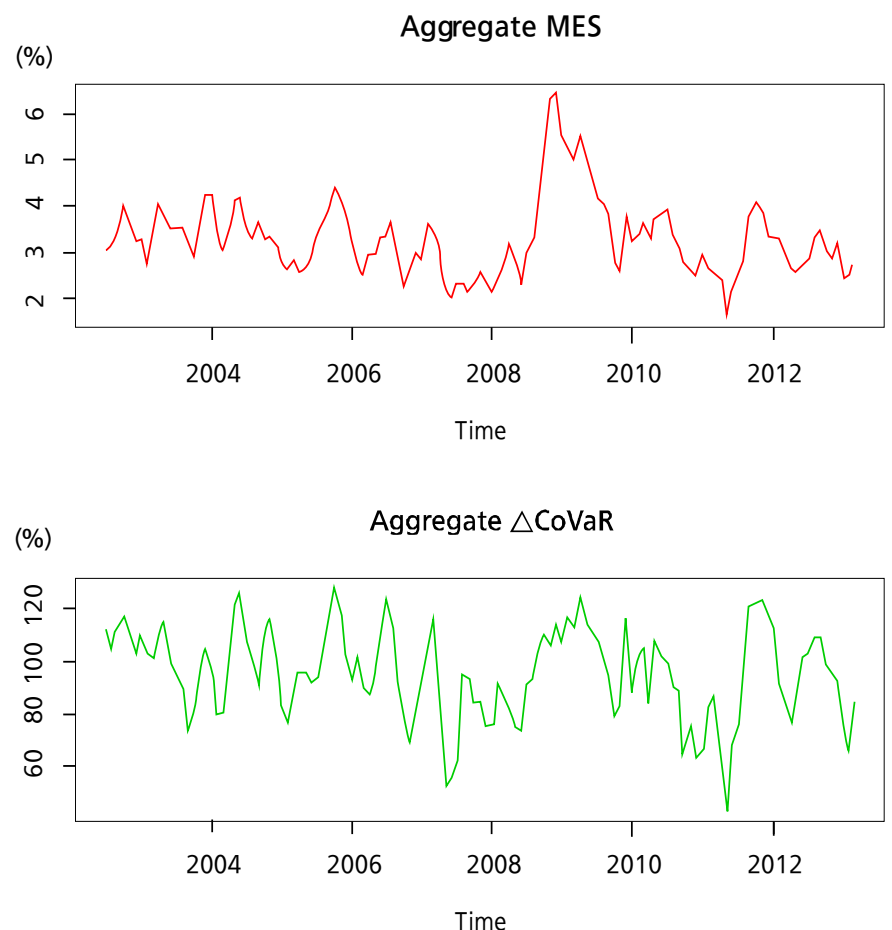

Note: Both the aggregate MES and the aggregate $\triangle \mathrm{CoVaR}$ are computed as an equity-weighted average.

exhibits different heights of peaks across the different crisis episodes.

If we use the aggregate MES to monitor overall systemic risk, it will be very useful to set a critical value that triggers some warning signal. To this end we conduct a threshold VAR (vector autoregression) analysis. Hollo et al. (2012) have previously used a threshold VAR to estimate the threshold value for a composite indicator of systemic stress (CISS) in the financial system. They consider financial stress to be at an important level when it begins to affect the real economy, and estimate the threshold value of the CISS through a threshold regression model. In our paper we use the CI (coincident composite index of business) growth rate for the variable representing the real economy.9) The aggregate MES one month 
Figure 8: Threshold Test Results

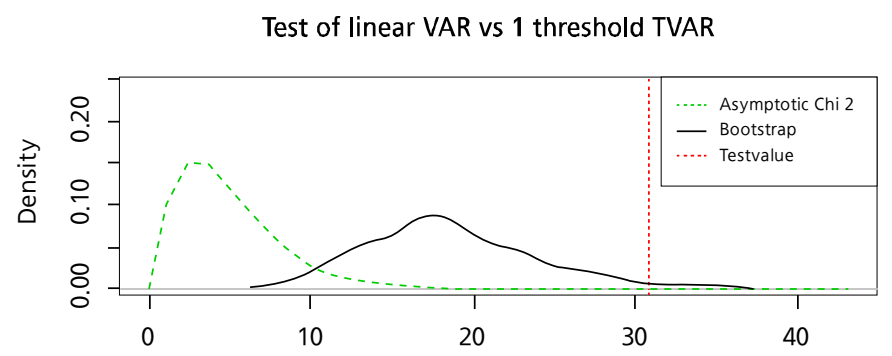

Test of linear VAR vs 2 threshold TVAR

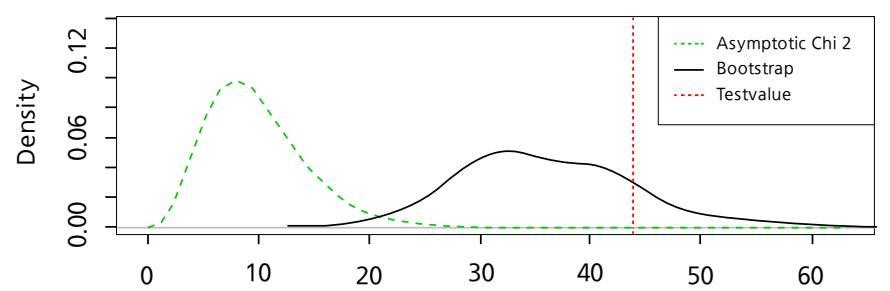

Note: The $p$-value is calculated as the proportion of the values that are greater than or equal to a test value indicated in a red dotted line under the density obtained from the bootstrap method.

before is used for the threshold state variable.

First, to test whether there is a threshold in the joint dynamics of these variables (i.e., the aggregate MES and the CI growth rate), we use Lo's and Zivot's (2001) threshold test, which extends Hansen's (1999) linearity test to a multi-variable setting. The number of lags in the VAR specification and the lag of the threshold state variable are determined by the AIC and BIC criteria. Accordingly, the lag of VAR is set to 2, and the aggregate MES one month before is set as the threshold state variable.

Figure 8 shows the results from Lo's and Zivot's (2001) threshold test. We use the package "tsDyn" in R, and the bootstrap method for the test. As shown in the upper panel, under the null hypothesis of "no threshold" and the alternative of 
Figure 9: Threshold Value

Results of the grid search

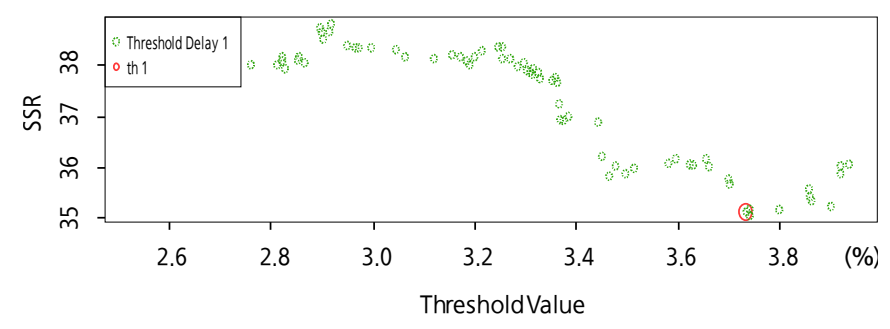

Aggregated MES with the threshold value

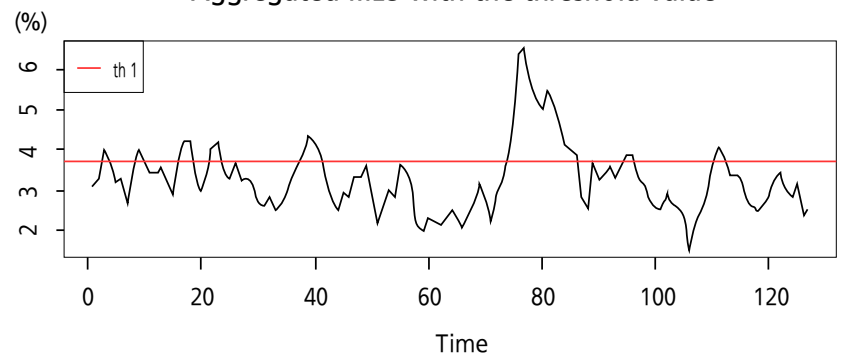

Note: In the lower panel, the black solid line shows a trend of the aggregate MES and the red horizontal line indicates the threshold value that is found in the upper panel.

"one threshold", we can reject the null hypothesis at a $5 \%$ significance level (p-value 0.02). However, the lower panel shows that, for the null hypothesis of "no threshold" and the alternative of "two thresholds", we cannot reject the null hypothesis at a $5 \%$ significance level (p-value 0.158). As a result we consider a one-threshold VAR model.

Under the assumption that there is one threshold, the threshold value of the aggregate MES that minimizes the sum of the squared residuals (SSR) is found to be $3.73 \%$ as shown in the upper panel of Figure 9. The lower panel of Figure 9 shows that $76.4 \%$ of the total observations belong to a "stable" regime (with aggregate MESs below 3.73\%) and 23.6\% to an "unstable" regime (aggregate MESs above $3.73 \%$ ).

Given the estimated threshold value, we conduct an impulse response analysis to analyze the effects of financial shocks on the real economy across different regimes. We use the structural threshold VAR model proposed by Balke (2000) as follows ${ }^{10)}$ : 


$$
Y_{t}=\mu^{(1)}+A^{(1)} Y_{t}+B^{(1)}(L) Y_{t-1}+\left(\mu^{(2)}+A^{(2)} Y_{t}+B^{(2)}(L) Y_{t-1}\right) I_{t}\left[S_{t} \geq \gamma\right]+\epsilon_{t}
$$

where $Y_{t}$ is a $2 \times 1$ endogenous variable vector consisting of the aggregate MES and the CI growth rate, and $I_{t}\left[S_{t} \geq \gamma\right]$ is an indicator function that takes the value of 1 if the threshold state variable $S_{t}$ (the lagged aggregate MES) exceeds the threshold value $\gamma$, and 0 otherwise.

In Equation (15), since $I_{t}[\cdot]$ is a dummy variable identifying two different regimes, $Y_{t}$ will exhibit different dynamics depending upon the regime. To be specific, under the regime with $I_{t}[\cdot]=0$, the dynamics involve $\mu^{(1)}(2 \times 1)$, $A^{(1)}(2 \times 2)$ and $B^{(1)}(L)(2 \times 2)$, while under the regime of $I_{t}[\cdot]=1$, they involve $\mu^{(1)}+\mu^{(2)}(2 \times 1), A^{(1)}+A^{(2)}(2 \times 2)$ and $B^{(1)}(L)+B^{(2)}(L)(2 \times 2)$, where $A^{(1)}$ and $A^{(2)}$ are coefficients related to contemporaneous restrictions. Due to the identification issue in the model, all diagonal elements should be zero. In line with the popular recursive VAR assumption, $A^{(1)}$ and $A^{(2)}$ are the matrix whose elements in the upper triangle are 0 if the variables are arranged in the order of exogeneity. This assumption causes the correlations between the elements of $\epsilon_{t}$ to equal zero, i.e. the covariance matrix of $\epsilon_{t}$ thus becomes a diagonal matrix. Since we assume that financial shocks are exogenous, we put the aggregate MES before the CI growth rate. Hence, the first element of $\epsilon_{t}$ is interpreted as financial shocks, and the second element as real shocks.

Figure 10 presents the impulse responses of the real economy (the CI growth rate) to financial shocks in each regime. As the upper panel of this figure shows, financial shocks do not have significant impacts on the real economy in the "stable" regime. The lower panel indicates, however, that in the "unstable" regime, where the lagged aggregate MES exceeds the threshold value, financial shocks do have significant influence. In particular, they tend to do so with one- to two-month time lags. This is also shown in the variance decomposition results reported in Table 4. In the "stable" regime, real economic shocks explain more than $97 \%$ of the rate in any forecasting horizon. In the "unstable" regime, however, financial shocks explain about $15 \sim 20 \%$ of the variations in the real economy.

10) For simplicity, let us assume that the lag order of the VAR model is one. 
Figure 10: Impulse Response Analysis
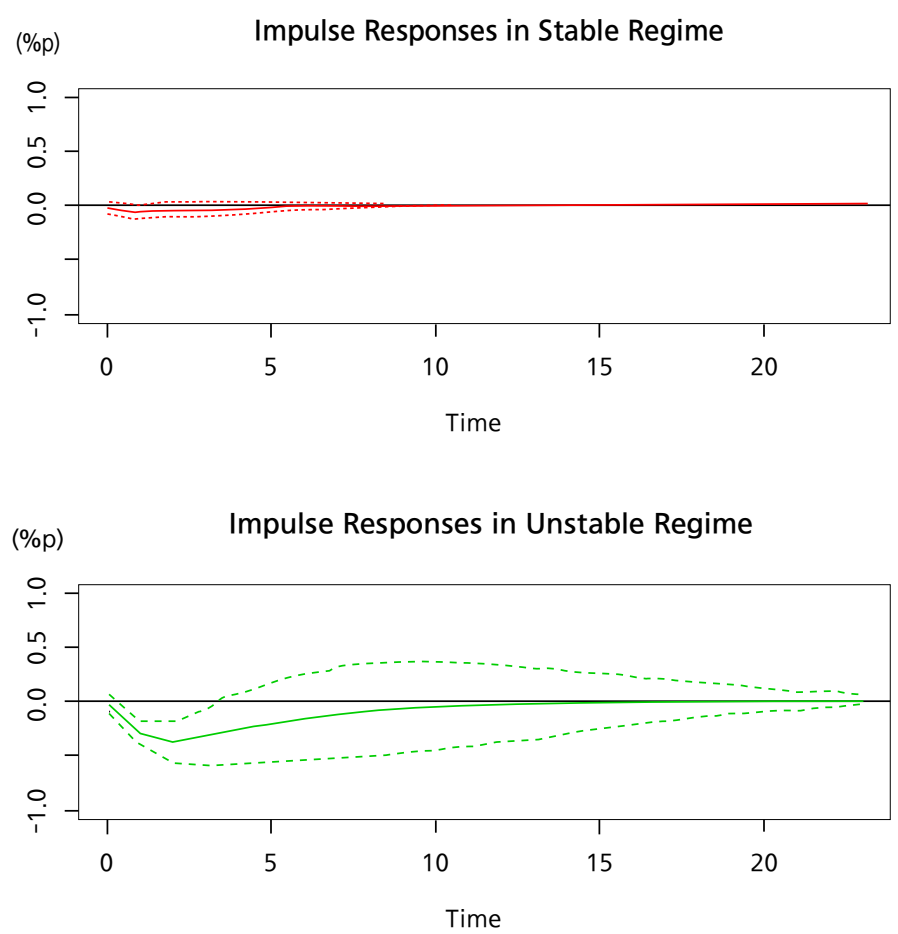

Note: Impulse responses of the rate of $\mathrm{Cl}$ growth to a one standard deviation shock of aggregate MES are plotted for both regimes.

\section{Table 4: Variance Decompositions}

\begin{tabular}{c|c|c|c|c|}
\multirow{2}{*}{ Lags } & \multicolumn{2}{|c|}{ Stable Regime } & \multicolumn{2}{c}{ Unstable Regime } \\
\cline { 2 - 5 } & Financial Shock & Real Shock & Financial Shock & Real Shock \\
\hline 4 & $2.2 \%$ & $97.8 \%$ & $20.0 \%$ & $80.0 \%$ \\
\hline 8 & $2.3 \%$ & $97.7 \%$ & $17.1 \%$ & $82.9 \%$ \\
\hline 12 & $2.3 \%$ & $97.7 \%$ & $15.8 \%$ & $84.2 \%$ \\
\hline 24 & $2.3 \%$ & $97.7 \%$ & $15.8 \%$ & $84.5 \%$ \\
\hline
\end{tabular}

Note: Cumulative variance decomposition results in both regimes are reported.

As has been explained so far, when the financial system faces a regime of instability the dynamic relationship between financial shocks and the real economic cycle changes to a substantial extent. The aggregate MES and the associated threshold value can then be expected to offer useful information for the monitoring of financial stability. 


\section{Conclusions}

In this paper we study systemic risks in the Korean banking sector by using two systemic risk measures - the MES (Acharya et al., 2010; Brownlees and Engle, 2012) and the CoVaR (Adrian and Brunnermeier, 2011; Girardi and Ergun, 2013). To compute both of them we employ Engle's (2002) DCC model. The DCC models can capture the time-varying nature of the systemic risk exposures of individual banks, a merit not shared by the quantile regression method also used to estimate the original CoVaR measure in Adrian and Brunnermeier (2011).

The findings of our analysis are the following. First, we have compared these two systemic risk measures and focused on how differently they evaluate the contribution to systemic risk of an individual bank. We have found that, although the measures provide different rankings for the systemic risk contributions, they turn out to be qualitatively very similar in explaining the cross-sectional differences in systemic risk contributions across banks.

Second, using both systemic risk measures we have analyzed the relationships between some bank characteristic variables and banks' systemic risk contributions, via simple correlation analysis and panel data regression methods. We have seen that the VaR of an individual bank affects the systemic risk contribution of that bank, from both the cross-sectional and the time series dimensions. This result is in contrast to Adrian and Brunnermeier (2011) and Girardi and Ergun (2013), who cannot find significant relationships between VaR and the systemic risk contribution measures for US banks. The leverage ratios are meanwhile not closely related to systemic risk contributions in the cross-sectional dimension, but an increase in the leverage ratio causes a rise in systemic risk contribution over time. Interestingly, after controlling for the effect of the leverage ratio we cannot obtain any significant effect of the BIS capital adequacy ratio. We also find that the size of the bank is associated with its systemic risk contribution only in the cross-sectional dimension.

Lastly, this paper has also proposed the aggregate MES for use as an overall systemic risk indicator for the banking system as a whole. This measure can be interpreted as the marginal expected shortfall of the return of a portfolio consisting of individual banks' equities conditional on market returns being below a certain threshold 
level. In order to use the aggregate MES for actual systemic risk monitoring, a threshold VAR model is used to analyze the dynamic relationship between this indicator and real economic activity. We can see that the dynamic relationship between the aggregate MES and the real economy changes substantially when the aggregate MES exceeds a certain threshold. The aggregate MES and its associated threshold value suggested in this paper are expected to offer useful information for the monitoring of financial stability.

In this study we have focused only on stock market information for deriving our systemic risk measures. However, there may be other valuable information - e.g. CDS premia, option prices or other macro and financial variables - for assessing these systemic risk measures. How to integrate such market or macro information into the assessment of systemic risk will be an important future research topic. 


\section{References}

Adrian, T. and M. K. Brunnermeier (2011), "CoVaR," NBER Working Paper, No. 17454.

Acharya, V., L. Pedersen, T. Philippe, and M. Richardson (2010), "Measuring Systemic Risk,” Technical Report, Department of Finance, NYU.

Arellano, M. and S. Bond (1991), "Some Tests of Specification for Panel Data: Monte Carlo Evidence and an Application to Employment Equations," Review of Economic Studies, 58(2), pp. 277-298.

Balke, N. S. (2000), "Credit and Economic Activity: Credit Regimes and Nonlinear Propagation of Shocks," The Review of Economics and Statistics, 82(2), pp. 344-349.

Breusch, T. S. and A. R. Pagan (1980), "The Lagrange Multiplier Test and Its Applications to Model Specification in Econometrics," Review of Economic Studies, 47(1), pp. 239-254.

Brownlees, C. T. and R. Engle (2012), "Volatility, Correlation and Tails for Systemic Risk Measurement," Working Paper.

Choi, Gongpil (2012), "Identification of N-SIFI and Directions for Macro-prudential Supervision," Financial Stability Studies, 12(1), pp. 89-135. (in Korean)

Engle, R. (2002), "Dynamic Conditional Correlation: A Simple Class of Multivariate Generalized Autoregressive Conditional Heteroskedasticity Models," Journal of Business \& Economic Statistics, 20(3), pp. 339-350.

Girardi, G. and A. T. Ergun (2013), "Systemic Risk Measurement: Multivariate GARCH Estimation of CoVaR," Journal of Banking \& Finance, 37, pp. 3169-3180.

Glosten, L. R., R. Jaganathan, and D. E. Runkle (1993), "On the Relation between the Expected Value and the Volatility of the Nominal Excess Return on Stocks," The Journal of Finance, 48(5), pp. 1779-1801.

Hansen, B. E. (1999), “Testing for Linearity,” Journal of Economic Surveys, 13(5), pp. 551-576. 
Hausman, J. A. (1978), "Specification Tests in Econometrics," Econometrica, 46(6), pp. 1251-1271.

Hollo, D., M. Kremer, and M. L. Duca (2012), "CISS - A Composite Indicator of Systemic Stress in the Financial System,” ECB Working Paper, No. 1426.

Huang, X., H. Zhou, and H. Zhu (2009), "A Framework for Assessing the Systemic Risk of Major Financial Institutions," Journal of Banking \& Finance, 33, pp. 2036-2049.

Lo, M. C. and E. Zivot (2001), "Threshold Cointegration and Nonlinear Adjustment to the Law of One Price," Macroeconomic Dynamics, 5(4), pp. 533-576.

Rodriguez-Moreno, M. and J. I. Pena (2013), "Systemic Risk Measures: The Simpler the Better?" Journal of Banking \& Finance, 37, pp. 1817-1831. 


\section{<Abstract in Korean>}

\section{윤재호*, 문혜정**}

본 연구에서는 두 가지 대표적인 시스템적 리스크 지표인 MES (marginal expected shortfall)와 CoVaR를 이용하여 우리나라 은행부문의 시스템적 리스크를 측정하였다. 두 가지 지표는 개별 은행과 은행시스템 주가수익률 간의 동태적 관계를 모형화할 수 있는 Engle (2002)의 DCC(dynamic conditional correlation) 모형을 이용하여 추정하였다.

국내 10 개 은행을 대상으로 분석한 결과 두 지표가 시스템적 리스크에 대한 기여도를 정의하는 방식이 서로 다름에도 불구하고 개별 은행 간 시스템적 리스크 기여도의 차이를 설명하는 데는 유사한 정보를 제공하고 있는 것으로 나타났다. 한편 개별 은행의 시스템적 리스크에 대한 기여도는 은행 특성변수인 VaR(value at risk), 자본규모, 레버리지 비율의 영향을 받는 것으로 나타났다. 그러나 횡단면 및 시계열 측면에서 측정해 본 이들 변수들의 시스템적 리스크 기여도에 대한 효과는 서로 다른 특징을 보였다.

마지막으로 $\mathrm{MES}$ 의 가산성 (additivity)에 근거하여 개별 은행의 $\mathrm{MES}$ 를 가중 평균하여 은행부문 전체의 시스템적 리스크 지표인 aggregate $\mathrm{MES}$ 를 산출하였다. 또한 threshold VAR 기법을 이용하여 aggregate MES와 경기동행지수 증가율 간의 관계를 분석하여 이들의 동태적 관계가 크게 달라지는 임계치를 제시하였다. 특히 금융불안정기에 금융충격이 실물경기에 유의한 영향을 미치는 것으로 나타 났다. 따라서 본 연구에서 제시한 시스템적 리스크 지표와 이와 관련된 임계치는 조기경보지표로서 금융안정을 모니터링 하는데 유용하게 활용될 것으로 기대된다.

* 이화여자대학교 경제학과 조교수

** 한국은행 거시건전성분석국 시스템리스크팀 과장 